\title{
Design Gráfico Inclusivo para Terceira Idade
} Inclusive Graphic Design
for elderly

Bruno Serviliano Farias ${ }^{1}$

Paula da Cruz Landim² 


\section{Resumo}

O presente artigo tem como objetivo discutir o Design Gráfico Inclusivo para a Terceira Idade. Tal tema se faz presente na atualidade devido ao grande número de idosos, bem como a perspectiva de envelhecimento da sociedade. Assim, esse trabalho expõe as definições do Design Inclusivo, os modelos e abordagens adotados nessa nova perspectiva, considerando o modelo social como uma variável projetual mais importante na contemporaneidade. Por fim, debate o impacto do processo de envelhecimento no design gráfico e como os elementos visuais devem ser adequados.

Palavras-chave: design gráfico inclusivo; terceira idade; elementos visuais.

\section{Abstract}

This article aims to discuss Inclusive Graphic Design for the Elderly. This theme is present today due to the substantial number of elderly people, as well as the aging process perspective of our society. Thus, this paper exposes the definitions of Inclusive Design, the models and approaches adopted in this new perspective, considering the social model as a more important design variable in contemporaneity. Finally, it discusses the impact of the aging process on graphic design and how the visual elements should be adequate.

Key-words: inclusive graphic design; third Age; visual elements. 


\section{Introdução}

Os processos de industrialização acarretaram mudanças profundas com discursos homogeneizados, atendendo o maior número de usuários possíveis, produzindo artefatos padronizados, excluindo pessoas não produtivas e não letradas como idosos e deficientes. No entanto, após as duas grandes guerras e diante de um cenário de destruição, com o elevado número de deficientes e incapacitados, bem como um perfil da população mundial mais envelhecida, foi desenvolvida uma nova ética que se propõe a conferir igualdade de valor, de direitos, superando formas de discriminação. Assim, surgiu uma visão contemporânea mais humanista e menos funcionalista, com práticas mais inclusivas.

Foi na década de 60 que todos os movimentos convergiram, tanto no campo acadêmico, como no campo social e político. Surgiram novos conceitos e novas formas de atuação. O termo Terceira Idade foi cunhado nessa época e serviu como novo marco para o envelhecimento, sendo adotado em políticas públicas, como a criação do Estatuto do Idoso, e a criação de instituições de saúde e de ensino, como as Universidades para Terceira Idade.

O envelhecimento populacional tem sido um desafio para todos os países. $O$ aumento da expectativa de vida elevou o número de famílias multigeracionais. Pessoas com mais de 40 anos convivendo com filhos e netos e muitas vezes responsáveis por sustentar seus familiares, comenta Clarkson et al (2003). Hoje no Reino Unido há mais pessoas acima de 65 anos do que abaixo de 16 anos (ELTON e NICOLLE, 2010).

O presente artigo apresenta conceitos do design permeado por essa nova ética mais humanizada, com o foco no design gráfico para a Terceira Idade. Para tal, apresenta os conceitos de design inclusivo, novos modelos de análise e discute a importância dos elementos visuais no design gráfico inclusivo para a Terceira Idade.

\section{Definições e conceitos}

O prolongamento da vida e a mudança de perfil social tem conduzido debates sobre o novo idoso, repensando as doenças e o bem-estar, debilidades e autonomia. O intuito é diminuir o grau de exclusão e proporcionar melhor qualidade de vida a uma parcela cada vez mais significativa. Tal contexto se tornou um desafio para diversas áreas acadêmicas e o Design foi impactado por essa nova ética que permitiu o desenvolvimento de novas teorias de atuação, como o Design Universal, Design Para Todos e o Design Inclusivo.

O Design Universal surgiu no início da década de 90 nos Estados Unidos com o foco Centrado no Usuário. Os E.U.A foram os primeiros países a garantir o design como direito civil para pessoas com deficiência. A acessibilidade é entendida como direito para criar um ambiente livre de barreiras, explica Fletcher et al (2013).

O termo "Design Para Todos" é uma filosofia que visa à concepção de produtos, ambientes e sistemas orientados à diversidade humana e a inclusão para facilitar a igualdade de oportunidades. Tem sua origem no norte da Europa, no funcionalismo escandinavo das décadas de 50 e 60, com o intuito de promover a integração social. 
A deficiência é considerada um fator social (ACCOLLA e BUTI, 2005).

O termo Design Inclusivo surgiu em meados de 1990, no Reio Unido, remontando a experiência da década de 60 relacionado com projetos e necessidades sociais. O envelhecimento populacional e a integração de pessoas com deficiência foram a causa do surgimento do Design Inclusivo (CLARKSON e COLEMAN, 2013). O Design Inclusivo não é um novo gênero do design nem uma nova especialidade, mas uma abordagem para lidar com as necessidades de um público mais amplo e não projetar para subgrupos como idosos e deficientes (CLARKSON e COLEMAN, 2013).

Considerar as capacidades funcionais reduzidas é fundamental para essas três teorias do design. É comum muitos autores considerarem esses termos como sinônimos por terem surgido na mesma época e com o mesmo espírito. O objetivo é tornar os artefatos acessíveis e utilizáveis para qualquer pessoa ou para um número maior de usuários, comentam Elton e Nicolle (2010). É um exercício de alteridade, valorizando a diversidade e a emancipação. Essas novas concepções sobre o usuário, sujeito, ser humano, no âmbito projetual permitiu o surgimento de novas abordagens e modelos de análises.

\section{Modelos e Abordagens do Design Inclusivo}

Para mapear o alcance e a escala do Design Inclusivo são necessárias quatro etapas de acordo com Clarkson e Coleman (2013): entender a demanda, obter dados populacionais, avaliar o nível de exclusão e gerar resultados. As duas primeiras etapas se relacionam com os usuários e suas capacidades funcionais. A terceiro etapa se relaciona com nível de exclusão, expõe as barreiras sociais que o usuário enfrenta ao realizar uma dada atividade. Por fim, a quarta etapa se relaciona com os resultados, com o intuito de projetar para minimizar as barreiras físicas e sociais considerando as limitações do usuário e o contexto em que ele está inserido. Com isso, observa-se assim dois modelos com abordagens diferentes, um voltado para as questões funcionais dos usuários e outro para as questões sociais.

\subsection{Modelo Biológico/Médico e o Processo de Envelhecimento}

Ser capaz de realizar fisicamente uma atividade como subir escadas, levantar da cadeira e outras correções motoras garante um estilo de vida independente, mas requer resistência muscular, flexibilidade e equilíbrio, afirma Clarkson et al (2003). Tais requisitos se alteram com a idade. O critério mais utilizado para classificar e identificar pessoas idosas é pelos limites etários que é adotado pela política Nacional do Idoso, pelo Estatuto do Idoso e pela Organização Mundial de Saúde.

No entanto, a velhice pode ser compreendida com um processo complexo marcado por mudanças, com uma redução significativa na capacidade funcional (motora, sensorial e cognitiva), desse modo, a característica biológica permite verificar os sinais de senilidade (CAMARANO E PASINATO, 2004). Capacidade, nesse modelo, é um dos atributos fundamentais que uma pessoa precisa para acessar, usar um produto e realizar uma atividade. Desconsiderar essas capacidades torna o processo de 
design excludente, ponderam Elton e Nicolle (2010).

O Modelo Biomédico considera pessoas com deficiência ou incapacitados por suas limitações físicas e mentais, afirmam Clarkson e Coleman (2013). Esse modelo considera essas pessoas incompletas e sua ênfase está nos componentes orgânicos, não valorizando questões sociais. Reforçando o Modelo Biomédico, é comum utilizar dados estatísticos como a expectativa de vida, problemas relacionados à saúde e escolaridade para justificar e embasar suas análises.

No Brasil é notório o crescimento do número de idosos. Em 1940 eram 4\% da população, representando 1,7 milhões de pessoas, em 2020 serão 30,9 milhões (CAMARANO, KANSO e MELLO, 2004). Sobre a expectativa de vida, saltou de 66 anos em 1990 para 73 anos em 2007 (FERRIGNO, 2010). Sobre a educação, 18\% dos idoso nunca foram à escola e $71 \%$ não tem diploma de ensino fundamental (NERI, 2007). Sobre problemas de visão, em 2000, 30\% dos idosos declararam possuir algum tipo de problema visual (CAMARO, KANSO e MELLO, 2004).

Cada pesquisa se restringe ao seu objeto de estudo que impacta a funcionalidade na Terceira Idade. Na funcionalidade motora, ocorre um processo de perda de força entre homens e mulheres a partir dos 45 anos (CLARKSON ET AL, 2003). Pesquisas com manuseio físico de artefatos se concentram nessa funcionalidade.

Na funcionalidade cognitiva, há a manipulação de símbolos de maneira abstrata que é regida por regras de acordo com uma sintaxe. A tarefa de reconstrução envolve atividades como lembrar, processar, tomar decisões (WILLIAM, DAVIDS e WILLIAMS, 2005). A maioria das atividades cognitivas atingem seu ápice aos 20 anos e tendem a se manter até os 50 anos. As habilidades mentais adquiridas ao longo do tempo tendem a permanecer estáveis. As habilidades que exigem rápida assimilação tendem a diminuir com o tempo, comenta Clarkson et al (2003).

$\mathrm{Na}$ velhice é comum o aumento do risco de doenças mentais que afetam a memória, o julgamento e o controle das emoções, ocasionando um déficit cognitivo em idosos com lentidão e perda de precisão (GURGEL e SISTO, 2010). Pesquisas com atividades que envolvem elevado grau de complexidade, memória e o aprendizado tendem a considerar essa funcionalidade.

$\mathrm{Na}$ funcionalidade sensorial as mudanças podem afetar os órgãos dos sentidos. O declínio da acuidade visual, que se inicia aos 40 anos, provoca a diminuição da percepção e a dificuldade em se adaptar ao brilho. A lente se torna opaca e menos elástica, representando menos luz dificultando a percepção de cores (azuis e violetas) e de objetos próximos (CLARKSON ET AL, 2003). A perda do campo central e periférico da visão é um dos problemas enfrentados na Terceira Idade em especial para quem sofre com diabetes, afirma Nine (2006). Pesquisas com elementos visuais, como o design gráfico, consideram essa funcionalidade. Não que as demais sejam excludentes.

Vieira (2011) comenta que é comum muitos idosos se sentirem analfabetos em decorrência de problemas de visão. Por essa razão, deve-se valorizar o planejamento de artefatos gráficos, considerando as necessidades desse público, pensando em estratégias visuais para compensar os problemas provenientes do processo de envelhecimento.

A idade é um marco eficaz para identificar pessoas idosas e aplicar políticas 
públicas. No entanto, como pode ser percebido, é um critério genérico de classificação que desconsidera os vários processos individuais e suas funcionalidades, como demonstra a Figura 1. Além disso, não há uma valorização do contexto em que os sujeitos estão inseridos, nem uma avaliação do quão excludente ou adaptado é o meio.

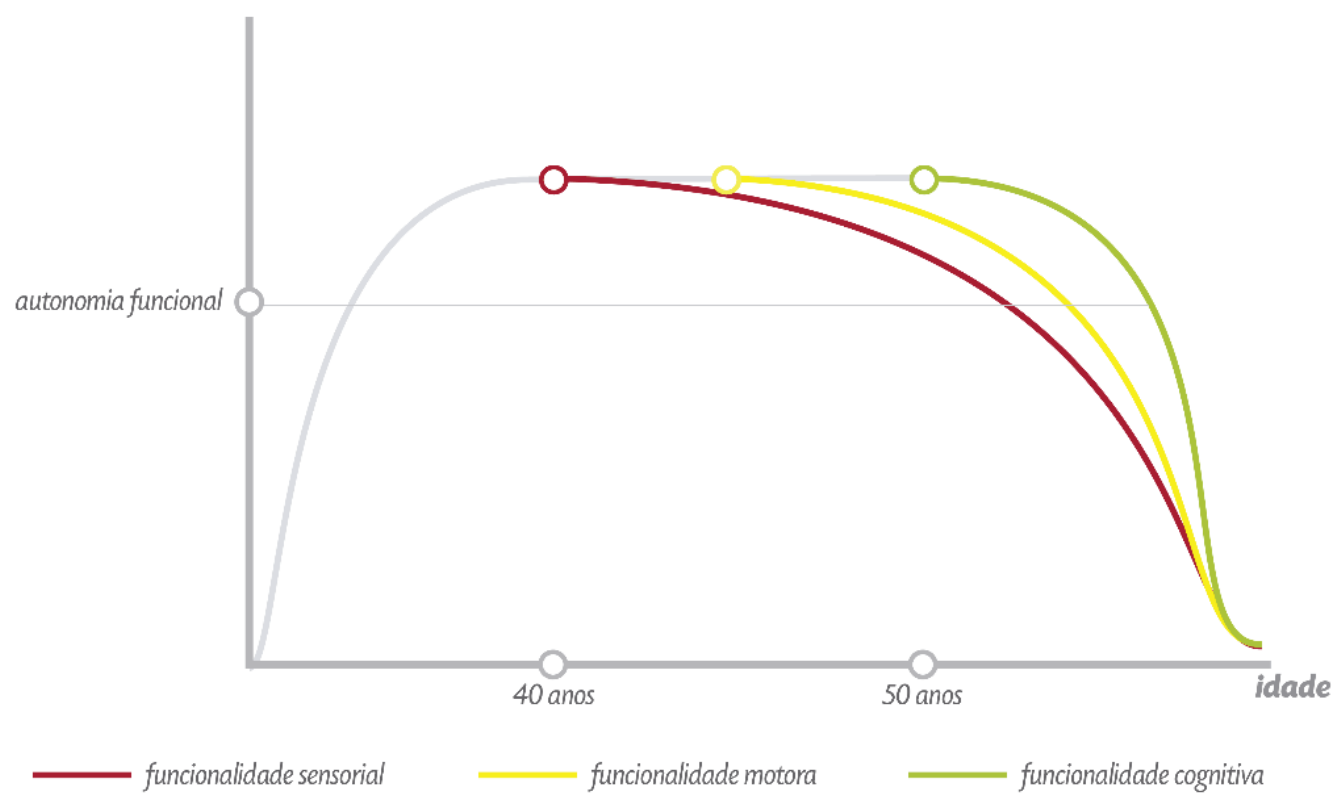

Figura 1 - Funcionalidades e o processo de envelhecimento Fonte: dos autores

\subsection{Modelo Social e a Nova Ética}

No modelo social a deficiência é imposta por desenhos inadequados que não consideram a diversidade física e mental. A configuração da demanda é uma decisão do designer que pode torna o usuário/sujeito independente ou dependente de outra pessoa para executar uma atividade através de um artefato. Por essa razão não se deveria projetar mais para um indivíduo médio ou uma classe média (CLARKSON e COLEMAN, 2013).

Deficiência nesse modelo surge de interações com o meio. Não se considera a deficiência como um problema individual, mas se transfere a responsabilidade para a sociedade. Por isso nesse modelo, a deficiência é resultado da interação social promovida pela organização social. Assim, uma pessoa que possui uma lesão pode não experimentar a deficiência, caso a sociedade garanta a diversidade projetual (Medeiros e Diniz, 2004). Para não experimentar a deficiência o projeto, além de estar adequado para as necessidades físicas do usuário deve também interagir com o contexto que está inserido.

Um ambiente inclusivo que recebe os idosos são as Universidades para Terceira Idade. O processo de ensino-aprendizagem pode contribuir para amenizar as principais adversidades decorrentes do processo de envelhecimento resgatando algumas funções sociais, trabalhando aspectos da funcionalidade cognitiva. A França e os EUA 
foram os pioneiros em projetos educacionais para os idosos na década de 70. 0 intuito, de acordo com Vieira (2011), era tardar o processo de envelhecimento através de exercícios físicos e mentais. O Brasil também teve suas primeiras instituições de ensino voltadas para os idosos na década de 70 através de iniciativas do SESC. Essas iniciativas tinham como objetivo oferecer informações sobre aspectos biopsicossociais do envelhecimento e entretenimento (VIEIRA, 2011). Na década seguinte, se espalhou pelas universidades brasileiras.

Como forma de aproximar o Modelo Social da prática de pesquisa tomaremos como exemplo o contexto de ensino na Terceira Idade. Antes de propor intervenções projetuais é necessário compreender três níveis:

I. Dos usuários - Reconhece as restrições do público, por isso se deve avaliar o grau de escolaridade, a média de idade, o motivo que os estimula a frequentarem esse ambiente e se possuem problemas cognitivos ou sensoriais.

II. Do ambiente - Compreende o grau de inclusão do ambiente, considerando o perfil dos professores, as estratégias de ensino adotadas, a representação do ambiente para os alunos e como são as salas de aula considerando a iluminação e o acesso.

III. Do artefato gráfico - Avalia o grau de exclusão do projeto, por isso se deve verificar como os alunos estudam, conhecer suas principais dificuldades de leitura e compreender o que acham sobre o material didático, bem como o uso, a percepção e a compreensão dos elementos gráficos.

Os objetos gráficos empregados para o ensino na Terceira Idade são fundamentais por permitirem conhecer e formular representações do mundo exterior, melhorando a comunicação com o ambiente e outros sujeitos. No entanto, é necessário adequar os elementos visuais aos fatores cognitivos e visuais presentes no processo de envelhecimento.

Assim, fica evidente que para cada nível há métodos de pesquisas diferentes, como pesquisa bibliográfica para o nível dos usuários, pesquisa etnográfica para o nível do ambiente, e pesquisa de legibilidade, usabilidade e compreensão para o nível do artefato.

\section{Questões Gráficas Inclusivas para a Terceira Idade}

O design gráfico emprega três elementos gráficos. Pela classificação de Twyman (1982, apud PETTERSSON, 2002, p. 65) são os elementos Verbal, Pictórico e Esquemático. Para o presente estudo serão utilizados os dois primeiros. Os elementos Verbais serão analisados sob a luz da Tipografia e os Pictóricos serão chamados de Iconográficos.

\subsection{Tipografia}

A Tipografia é a ciência que estuda as formas de comunicação verbal, considerando sua estética e sua legibilidade. A legibilidade, por sua vez, estuda a expressão concisa das letras sem que elas sofram perdas quando lidas (FRUTIGER, 2007). Assim, 
a seleção e emprego das fontes tipográficas para artefatos gráficos utilizados para a Terceira Idade devem observar vários critérios. Burt, Coorper e Martin (1955) as listam, são elas:

- o desenho da forma e seus elementos de diferenciação;

- o tamanho, considerando o grau de restrição visual dos usuários;

- o uso de caixa baixa e o blocamento de palavras,

- o tipo de traço e

- o espaço interno das letras.

O American Printing House for the Blind, que existe desde de 1858, desenvolveu diretrizes de usabilidade para pessoas com baixa visão. O Escritório comenta que as serifas funcionam bem em títulos, mas podem ser de difícil leitura em textos longos, comenta Kitchel (2018). O autor citou alguns cuidados necessários para seleção das fontes como elementos de diferenciação com o intuito de facilitar a identificação de letras como o "g" e o "9" ou "O" com "0", Figura 2.

As fontes devem ser largas, com espaços entre as letras e com espaços internos generosos, como em "a" e "c", como apresentado na Figura 2. Os espaços em branco tornam o texto legível por fornecer contraste, isso inclui linhas e margens. As fontes itálicas são de difícil leitura para pessoas com baixa visão. As melhores fontes são Antique Olive, Tahoma, Verdana e Helvética (KITCHEL, 2018).

O tamanho mínimo para pessoas com baixa visão, é 12 pontos. Para impressões ampliadas, 14 a 16 pontos, formatos maiores, 18 pontos. Pessoas que precisam de fontes com tamanhos maiores que 28 devem ser consideradas candidatas à educação em Braille (KITCHEL, 2018).

Com relação ao público idoso, as fontes com 14 pontos são mais rápidas e com menos erros de leitura do que as de 12 pontos. As fontes preferidas são as fontes sem serifas, afirmam Bernard, Lias E Mills (2001). No entanto, a legibilidade não é apenas uma questão de tamanho da fonte. Letras maiores melhoram a percepção quando lidas isoladamente, mas não favorecem nem uma leitura rápida nem uma compreensão rápida (BURT, COORPER e MARTIN, 1955). Por isso a importância de se conhecer as várias articulações tipográficas para proporcionar as melhores estratégias para uma boa leitura para idosos com problema de visão.

Palavras em blocos retangulares, com o uso de caixa alta, mesmo tornando-as mais visíveis levam mais tempo de leitura pois não torna o texto mais legível. O uso de negrito, ou seja, fontes com traços mais robustos são mais eficientes, lembra Groeger (2017). Por isso há uma relação entre espessura do traço, tamanho da fonte e o uso dos espaços em branco que deve ser investigada.

Fontes com traços finos são menos adequadas, pois as palavras podem aparecer "quebradas", com partes faltando. Traços mais grossos não podem fechar ou mesmo diminuir os espaços internos dos caracteres. Traços mais consistentes, uniformes, melhoram a legibilidade, assim como o prolongamento das ascendentes e descendentes. Uma fonte legível para quem tem baixa visão não é necessariamente legível para quem tem uma visão envelhecida (NINE, 2006). 


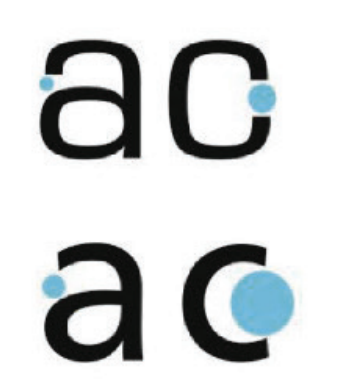

Espaço Interno

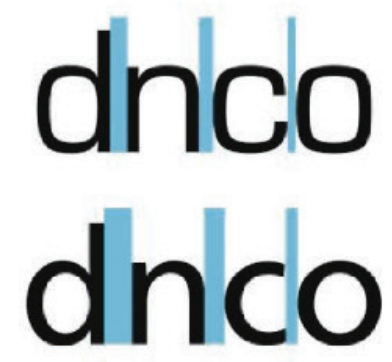

Entre Letras

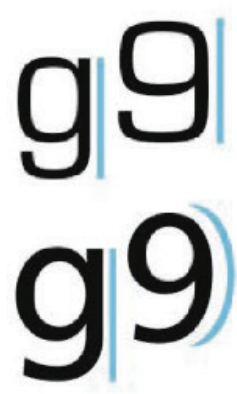

Elementos de Diferenciação

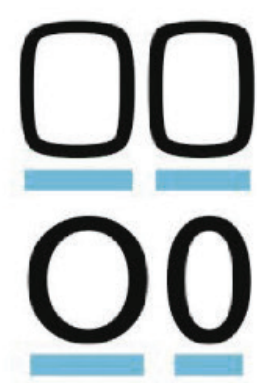

Desenho da Forma

Figura 2- Articulações Tipográfica Fonte: Groeger (2017)

Diante dessas variáveis é importante investigar quais articulações tipográficas são mais significativas para o público. Dessa forma, os principais métodos de investigação da legibilidade incluem:

- facilidade de leitura considerando a distância do artefato gráfico em relação ao leitor;

- precisão da leitura considerando as palavras;

- velocidade de leitura considerando a compreensão e o movimento dos olhos.

Para avaliar tais questões é comum pesquisas que avaliam a legibilidade, a usabilidade e a compreensão, pois essas pesquisas conseguem mensurar o tempo, a quantidade de erros, o efeito da distância do artefato e o comportamento dos olhos durante a leitura.

\subsection{Iconografia}

Outro elemento que deve ser inclusivo são os elementos iconográficos (desenhos, ilustrações e fotos). As estratégias iconográficas incluem forma, familiaridade e redundância da informação, relação entre complexidade e simplicidade e as cores e a relação de contraste.

Barthes (2004) afirma que fazemos operações de deciframento ao perceber um símbolo gráfico. Quando essas operações são familiares nos sentimos seguros, do contrário, sem a familiaridade, os signos se esvaziam de significados. Contudo, problemas de visão podem tornar as ilustrações estranhas, desconhecidas, tornando qualquer imagem sujeita ao desaparecimento. Por isso que a redundância da informação não é supérflua, pois, em qualquer mensagem, há ruídos e perda de informação.

Há um fenômeno sobre o qual qualquer imagem está sujeita, à "perspectiva do desaparecimento", no qual, de acordo com Gombrich (2012), primeiro se perde a noção da forma, depois a cor e finalmente a massa do corpo. O desaparecimento por meio da distância, da falta de iluminação, do ofuscamento ou da visão deficiente, complementa o autor, depende de muitas variáveis como: tamanho, cor, movimento e até treinamento. Gombrich (2012) afirma que há uma tendência em perceber con- 
figurações simples como linhas retas e círculos em contraste com o mundo caótico. As formas geométricas são construídas valorizando o princípio da simplicidade, comenta o autor.

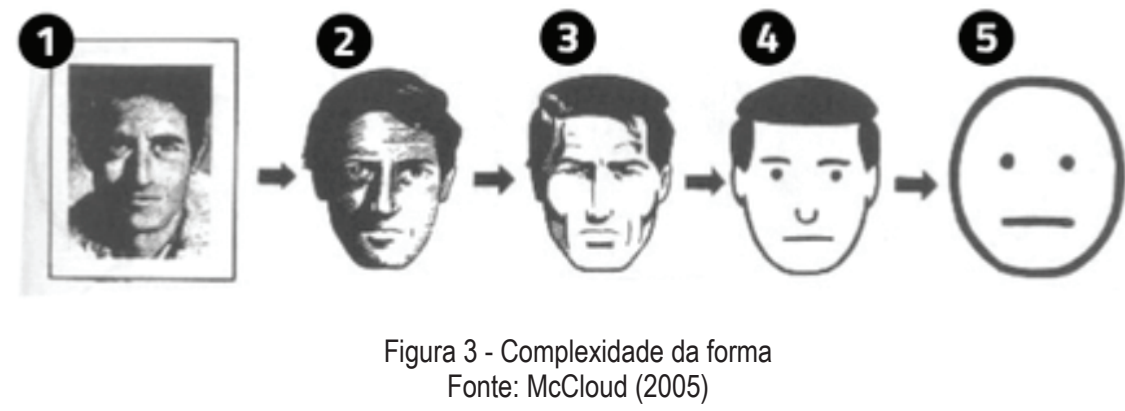

Clarkson et al (2003) comenta que as sínteses visuais, capacidade para distinguir uma imagem, torna-se mais difícil com a idade, por isso imagens com elevado consumo de memória devem ser evitadas. Ribeiro et al (2010) discutem a questão da complexidade iconográfica na geração de interferências visuais e afirmam que a complexidade das imagens interfere em indivíduos com baixa acuidade visual e com baixa escolaridade. Os autores consideram que as interferências são representações mentais que ocorrem entre informações linguísticas e conhecimento semântico.

Assim, para manter ativado o funcionamento cognitivo se faz uso da memória de longo prazo, dos elementos culturais e dos aspectos da aprendizagem. Os estímulos visuais são o gatilho inicial desse funcionamento. A escolaridade e o processo de envelhecimento interferem no declínio do funcionamento sensorial e cognitivo principalmente nos estímulos visuais, na memória e no processamento cognitivo, citam Ribeiro et al (2010).

A cor gera atenção e cria contraste. Acredita-se que $80 \%$ das informações que o ser humano recebe são de natureza visual e $40 \%$ se refere à cor, comenta Pinheiro e Silva (2010). Materiais coloridos melhoram a memorização além do interesse e da eficácia do aprendizado. Cores com luminosidades diferentes, de acordo com Csillag (2015), são facilmente identificáveis, enquanto as de matrizes com luminosidades iguais não o são.

No entanto, o contraste mais importante para pessoas de visão diminuída é o contraste entre luminosidade (branco e preto), mais importante do que os contrastes entre matizes (cores) ou contrastes de saturação. Sobre as restrições das cores Pinheiro e Silva (2010) comentam que a percepção de violeta, azul e verde se torna mais difícil. Assim, combinações entre azul, violeta e verde devem ser evitadas. Sobre isso, Kitchel (2018) menciona que as melhores cores são o azul, amarelo, verde e o marrom, como apresentado na Figura 4. O cinza nunca deve ser utilizado. 


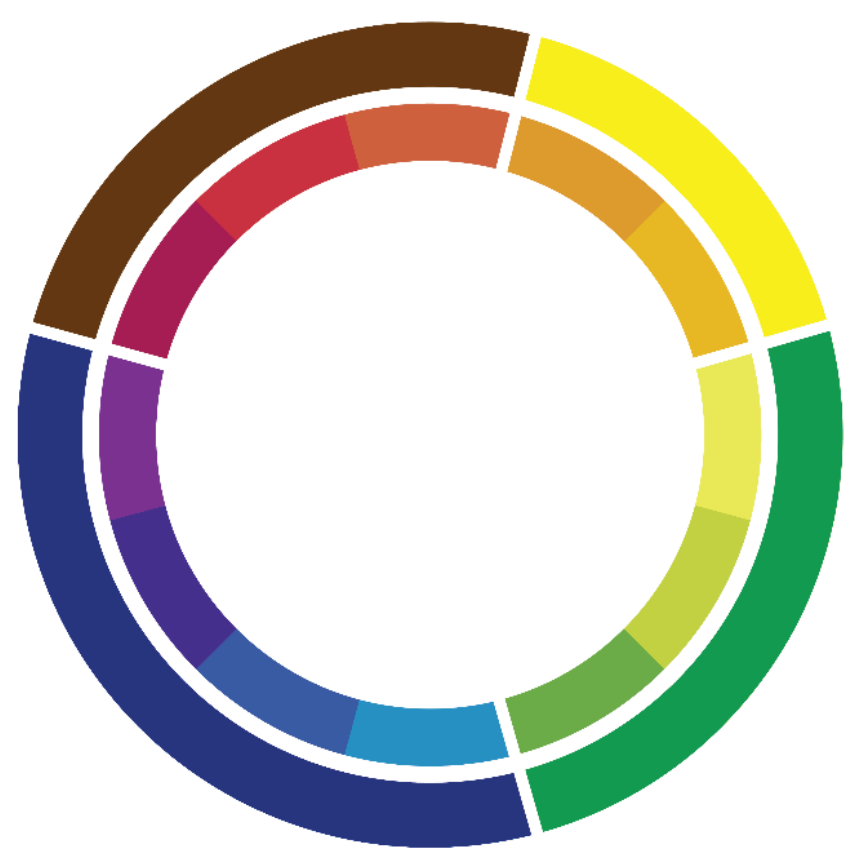

Figura 4 - Restrições Cromáticas para baixa visão Fonte: dos autores

O círculo interno representa todas as cores que podem ser empregadas no processo de impressão. O círculo externo representa as recomendações de cores para pessoas com baixa visão. Conclui-se que as ilustrações teriam desempenhos melhores do que as fotografias devido ao controle cromático que impacta a funcionalidade sensorial de pessoas com baixa visão e pelo controle da complexidade que impacta a funcionalidade cognitiva, principalmente de pessoas idosas.

Para comprovar tais questões se faz uso de várias técnicas como grupo focal, observação e questionários. Há vários outros testes para avaliar as competências sensoriais e cognitivas, as principais são do campo da psicologia, sendo estas:

- Teste Pictórico de Memória - avalia a capacidade de recuperar uma informação em um curto espaço de tempo, composto por figuras e vários detalhes visuais;

- Teste Toulose-Piéron - é um teste psicométrico que avalia a atenção permanente, utiliza uma folha com mil quadrados para preencher de acordo com o modelo

- Teste de Reprodução Visual - é uma escala de memória na qual o sujeito deverá traçar, de memória, figuras geométricas.

\section{Considerações Finais}

O presente artigo teve como objetivo discutir os conceitos do Design Gráfico Inclusivo para a Terceira Idade. Para tal foi apresentada uma breve introdução sobre o processo de Industrialização e como esse processo permitiu a exclusão do idoso de várias atividades humanas, como o consumo.

No entanto, após a Segunda Guerra Mundial, surgiu uma nova ética que valorizava a participação de todos os membros da sociedade, incluindo idosos e deficientes. Tal ética se fez presente em ações políticas e educacionais, bem como no próprio consumo de produtos. O design se apropria dessa nova ética para desenvolver novas abordagens inclusivas. 
O modelo biológico, que valoriza as questões fisiológicas do corpo, deixa de ser tão relevante e passa a valorizar o contexto social, que prioriza as relações humanas. Assim, dependendo da complexidade do projeto é possível focar nas deficiências do usuário, na diminuição do nível de exclusão de ambientes ou no desenvolvimento de artefatos inclusivos.

Os artefatos nesse contexto ganham importância por minimizar barreiras sociais e permitir o acesso de vários lugares e atividades para todas as pessoas. A deficiência deixa de ser uma subtração das capacidades corporais para se tornar uma falta de organização da sociedade. Logo, uma sociedade organizada privilegia as diversidades de capacidades e permite o acesso e a inclusão de todos os seus cidadãos.

Por fim, o presente estudo discute como os elementos tipográficos e iconográficos podem ser adequados para a Terceira Idade e cita os principais métodos de investigação que permitem conhecer e analisar a eficiência deles em cada situação. Os elementos tipográficos apresentam um conjunto de articulações visuais que, quando bem empregadas, facilitam a leitura como:

- Tamanho das fontes: abaixo de 12 pontos uma pessoa com problema visual pode ter dificuldade.

- Estilo do traço: estilos de traço fino e com alto-contraste podem comprometer a percepção de pessoas com baixa visão. Traços mais robustos com espaços internos auxiliam a promover a leitura dessas pessoas.

- Elementos de diferenciação: fontes com caracteres semelhantes geram ambiguidades na sensação visual, por isso o uso de minúsculas é mais adequado.

Os elementos tipográficos também apresentam articulações visuais que quando empregadas permitem a percepção visual.

- Simplificação da forma: pessoas com problemas de visão tem dificuldades em perceber detalhes.

- Contraste: o contraste luminoso é a principal estratégia cromática devido ao processo de envelhecimento que torna o cristalino opaco.

\section{Referências}

ACCOLLA, Avril; BUTI, Luigi Bandini. Design for All e ergonomia. In: Ergonomia. 2005, p. 5-13.

BARTHES, Roland. O grão da voz. São Paulo: Martins Fontes, 2004.

BERNARD, Michael; LIAS, Corrina; MILLS, Melissa. The effects of font type and size on the legibility and reading time of online text by older adults. In: Conference on Human Factors in Computing Systems. New York, 2001. p. 175-176.

BURT, CYRIL; COOPER, W. F., MARTIN, J. L. A psychological study of typography. In: The British Journal of Statistical Psychology. 1955. p. 29-65.

CAMARANO, Ana Amélia; PASINATO, Maria Tereza. O envelhecimento popula- 
cional na agenda das políticas públicas. In: Os novos idosos brasileiros: muito além dos 60?. Rio de Janeiro: IPEA, 2004.

CAMARANO, Ana Amélia; KANSO, Solange; MELLO, Juliano Leitão e. Como Vive o Idoso Brasileiro?. In: Os novos idosos brasileiros: muito além dos 60 ?. Rio de Janeiro: IPEA, 2004.

CLARKSON, John; COLEMAN, Roger; KEATES, Simeon; LEBBON, CHERIE. Inclusive Design: Design for the whole population. Cambridge: Springer-Verlag London, 2013.

CLARKSON, John; COLEMAN. History of Inclusive Design in the UK. In: Applied Ergonomics. Elsevier, 2013. p. 1-13.

CSILLAG, Paula. Comunicação com cores: uma abordagem científica pela percepção visual. São Paulo: Senai-SP/ESPM, 2015.

ELTON, E.; NICOLLE, C.A. The importance of contexto in inclusive design. In: Proceedings of the International Conference on Contemporary Ergonomics and Human Factors Keele. London: Taylor \& Francis, 2010.

FERRIGNO, José Carlos. Coeducação entre Gerações. São Paulo: Sesc São Paulo, 2010.

Fletcher, V., Bonome-Sims, Gabriela; Knecht, Barbara; Ostroff, Elaine; Otitigbe, Jennifer; Parente, Maura; Safdie, Joshua. The challenge of inclusive design in the US context, In: Applied Ergonomics. Elsevier, 2013.

FRUTIGER, Adrian. Sinais e símbolos. São Paulo: Martins Fontes, 2007.

GOMBRICH, E. H. O sentido de ordem: um estudo sobre a psicologia da arte decorativa. Porto Alegre: Bookman, 2012.

GROEGER, Lena. How typography can save your life. In: Home: ProPublica < https://www.propublica.org/article /how-typography-can-save-your-life> 30/04/2017.

GURGEL, Marina Gasparoto do Amaral; SISTO, Fermino Fernandes. O estudo correlacional entre inteligência e memória em idoso. In: Periódicos eletrônicos em Psicologia. 2010.

KITCHEL, J. Elaine. APH Guidelines for Print Document Design. In: Home: APH < http://www.aph.org/research/design-guidelines/> 14/02/2018. 
MCCLOUD, Scott. Desvendando os quadrinhos. São Paulo: M.Books, 2005.

MEDEIROS, Marcelo, DINIZ, Debora. Envelhecimento e Deficiência. In: Os novos idosos brasileiros: muito além dos 60?. Rio de Janeiro: IPEA, 2004.

NERI, Anita Liberalesso. Atitudes e preconceitos em relação à velhice. In: Idoso no Brasil: vivência, desafios e expectativas na terceira idade. São Paulo: Ed. Fundação Perseu Abramo, 2007, 288 p.

NINE, Paul. Typography and the aging eye: typeface legibility for older viewers with vi-sion problems. In: Home: Aiga < http://www.aiga.org/typography-and-the-aging-eye>, 30/04/2017. 2006.

RIBEIRO, Ariella, Fornachari; FREITAS, Maria Isabel d'Ávila; RODANOVIC, Márcia; MANSUR, Letícia Lessa. The generation of visual interrences in normal elderly influence of schooling and visual complexity. In: Demente Neuropsychol. 2010.

PETTERSSON, R. Information design: an introduction. Philadelphia: John Benjamins Pub-lishing Company.2002.

VIEIRA, Rosane Maria da Silva. Um estudo sobre o design de livros para a terceira idade. Dissertação de Mestrado. Programa de Pós-Graduação em Design da Universidade Federal do Rio Grande do Sul. Porta Alegre. 2011.

WILLIAM, A. M.; DAVIDS, K. WILLIAMS, J. G. Visual Perception and action in sport. Londres: EeFN Spon, 2005. 